\title{
COMPOSTAGEM DOS RESÍDUOS ORGÂNICOS NO CEFET-MG
}

Larissa Ribeiro de Faria - larissaribeiro1705@gmail.com

Centro Federal de Educação Tecnológica de Minas Gerais (CEFET-MG)

Mayra Batista Gomes Brito - britto.mayra@gmail.com

Centro Federal de Educação Tecnológica de Minas Gerais (CEFET-MG)

Angelo Tadeu Magno Leão - magno.1995@ hotmail.com

Centro Federal de Educação Tecnológica de Minas Gerais (CEFET-MG)

Franciele Aparecida Protásio Duarte - francieleplotasio@gmail.com

Centro Federal de Educação Tecnológica de Minas Gerais (CEFET-MG)

Jessica Elorde Freitas - jehelorde@ gmail.com

Centro Federal de Educação Tecnológica de Minas Gerais (CEFET-MG)

Ítalo Cordeiro e Lellis - italolellis@ hotmail.com

Centro Federal de Educação Tecnológica de Minas Gerais (CEFET-MG)

Jéssica Thebaldi Victoriano - jethebaldi@ gmail.com

Centro Federal de Educação Tecnológica de Minas Gerais (CEFET-MG)

Nathália Corrêa Das Dores - nathaliacd7@gmail.com

Centro Federal de Educação Tecnológica de Minas Gerais (CEFET-MG)

Luiz Fernando Jacome Lopes - luizfernandojacomedias@gmail.com

Centro Federal de Educação Tecnológica de Minas Gerais (CEFET-MG)

Priscila da Costa - costapri.1710@gmail.com

Centro Federal de Educação Tecnológica de Minas Gerais (CEFET-MG)

Valéria Cristina Palmeira Zago - valzagomg@gmail.com

Professora Associada - Departamento de Ciência e Tecnologia Ambiental

Centro Federal de Educação Tecnológica de Minas Gerais (CEFET-MG) 


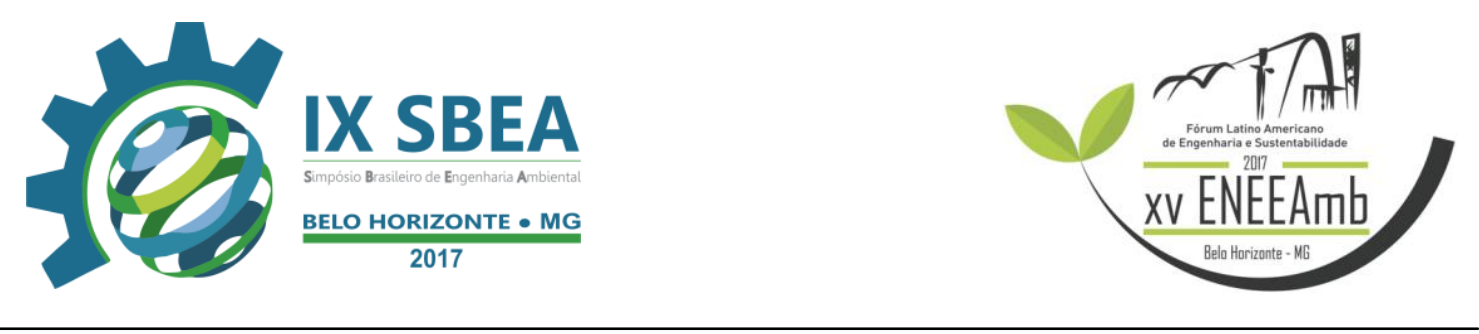

\section{RESUMO}

Aplicar a gestão de resíduos sólidos conforme as diretrizes legais é um grande desafio enfrentado pelos municípios do Brasil. Boa parte dos resíduos sólidos orgânicos são dispostos de maneiras inadequadas, assim, faz-se necessário a aplicação de tecnologias de reciclagem desses resíduos, como por exemplo, a compostagem.

O presente trabalho tem como principal objetivo relatar o processo de avaliação da compostagem como tecnologia viável para implementação no Centro Federal de Educação Tecnológica de Minas Gerais, campi I e II, Belo Horizonte - MG.

Para tanto, foi constituído, dentro do PET Ambiental, um subgrupo denominado "Compostagem". Entre os anos de 2014 a 2016 foram realizados três experimentos para adequação da compostagem à realidade da instituição.

Os campi I e II, do CEFET-MG geram grande quantidade de resíduos orgânicos alimentares, oriundos dos refeitórios e lanchonetes, bem como, "resíduos verdes", oriundos de podas de árvores e roçadas de gramados da instituição. No entanto, ambos os campi possuem áreas bastante reduzidas para realização do modelo tradicional de compostagem em leiras, assim, optou-se por testar modelos de compostagem que podem ser realizados em espaços restritos.

Foram avaliados os seguintes parâmetros técnicos determinantes para a adoção da tecnologia da compostagem no CEFET-MG: 1. Proporção de resíduos do preparo de alimentos e dos jardins; 2. Tempo de maturação, considerando para tanto a temperatura, umidade e pH; 3. Desenvolvimento de odores e atração de animais e insetos.

Inicialmente a compostagem não era considerada uma alternativa de reciclagem dentro da instituição, porém, após vários contatos com os servidores das prefeituras, dos refeitórios e da direção geral, percebe-se que, aos poucos, o projeto tem tido uma maior relevância dentro do CEFET-MG. Os resultados experimentais mostraram que a compostagem é viável tecnicamente, porém, ainda não pode ser implantada e adotada como parte do sistema de gerenciamento de resíduos da instituição, devido às dificuldades logísticas e burocráticas.

Este documento apresenta instruções detalhadas para a elaboração e envio de trabalhos para o IX Simpósio Brasileiro de Engenharia Ambiental, XV Encontro 


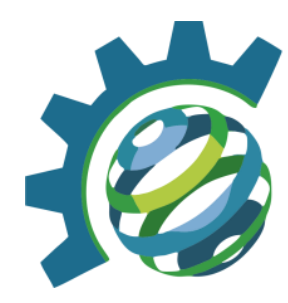

Nacional de Estudantes de Engenharia Ambiental e III Fórum Latino Americano de Engenharia e Sustentabilidade.

Palavras-chave: resíduos, compostagem, instituição de ensino.

\section{INTRODUÇÃO/OBJETIVO}

Os resíduos orgânicos correspondem à metade dos resíduos urbanos gerados no Brasil e podem ser tratados, tanto em escala doméstica, quanto em grande escala para a produção de fertilizantes orgânicos. (BRASIL, 2012).

De acordo com os dados da versão preliminar do Plano Nacional de Resíduos Sólidos há, anualmente, uma geração de 800 milhões de toneladas de resíduos orgânicos (BRASIL, 2012) que, por não serem coletados separadamente, acabam sendo encaminhados para disposição final juntamente com resíduos perigosos e com aqueles que deixam de ser coletados seletivamente. Esse tipo de destinação gera despesas para os municípios, as quais poderiam ser evitadas, se a matéria orgânica fosse encaminhada para um tratamento específico, como por exemplo, a compostagem. (MASSUKADO, 2008).

A compostagem, assim como a implantação da coleta seletiva e da disposição final ambientalmente adequada dos rejeitos, faz parte do rol de obrigações dos municípios instituída pela Lei 12.305/2010. A caracterização, quantificação, separação e destinação final adequada garantem uma eficiência no processo de gestão e gerenciamento de resíduos sólidos orgânicos. O conjunto dessas ações, juntamente com a compostagem de resíduos orgânicos, pode ser aplicado em estabelecimentos comerciais, industriais, órgãos públicos e instituições de ensino. As universidades geram uma grande quantidade de resíduos orgânicos, muitas vezes comparados, em escala, a pequenos municípios (TAUCHEN \& BRANDLI, 2006; CUNHA et al, 2013).

Neste âmbito, dentro do grupo PET-Ambiental, foi criado um subgrupo denominado "Compostagem", o qual se responsabilizou por conduzir o "Projeto-Piloto de Compostagem em Pequena Escala" em execução no CEFET-MG, nos campi I e II.

O projeto tem como objetivo avaliar diferentes parâmetros técnicos da compostagem, de maneira a apresentar uma proposta de reciclagem dos resíduos 
orgânicos, que seja compatível e viável para as condições de restrição de espaço físico da instituição.

\section{METODOLOGIA}

\subsection{Diagnóstico quantitativo de resíduos orgânicos}

Para dar início ao projeto de "Compostagem dos Resíduos Orgânicos do Refeitório dos Campi I e II do CEFET-MG”, foi necessário fazer um levantamento da quantidade de resíduos orgânicos gerados, tanto antes, no período de preparo do alimento a ser servido no restaurante, quanto, logo após o consumo, em que são descartados restos alimentares, além de guardanapos, embalagens plásticas e palitos (resíduos inorgânicos).

Essa etapa de levantamento do "desperdício" de alimentos foi feita no período de uma semana, entre os dias 04/05/2015 e 08/05/2015. A pesagem dos orgânicos descartados, utilizando uma balança Filizola, com capacidade de $40 \mathrm{~kg}$, foi realizada durante os dois períodos de funcionamento do restaurante (almoço e jantar), além disso, as pesagens foram divididas entre: 1. Resíduos Orgânicos gerados pelo preparo da alimentação; 2. Restos Alimentares desperdiçados nos pratos; 3. Guardanapos, Embalagens Plásticas e Palitos. Além dos dados gerados em relação à procedência dos resíduos, foi feito um levantamento do total de refeições servidas no restaurante (almoço e jantar).

Para o cálculo do desperdício pós-consumo utilizou-se a quantidade estimada de consumo per capita de $0,5 \mathrm{~kg} /$ refeição - padrão usual para os cálculos de compras de produtos alimentares pela Instituição (LELIS, DUARTE, FREITAS, VICTORIANO, ZAGO, 2016). Foram utilizadas as seguintes fórmulas:

$\%$ de Desperdício Total $=$ Total de resíduos gerados $\times$ 100/Total de alimentos necessários

\% de Desperdício por refeição $=$ Total de resíduos pós-consumo/ $\mathbf{N}^{0}$ de refeições

Já para o levantamento de emissões de GEE (Gases de Efeito Estufa) foi utilizada a planilha online, do Modelo de Redução de Resíduos (WARM), proposta pela Agência de Proteção Ambiental dos Estados Unidos. Além disso, foi calculado - 


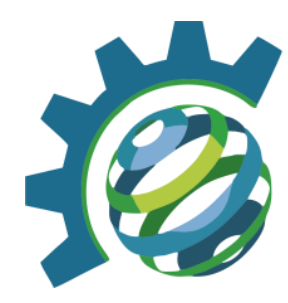

utilizando Tabelas de Consumo Energético (INMETRO, 2015) - o gasto energético e, consequentemente os "GEEs" gerados através dos equipamentos utilizados para o preparo e conservação dos alimentos. Esse dado foi levantado, visando que o Brasil é o sétimo maior emissor de GEE no mundo (SEEG, 2016).

\subsection{Levantamento de Metodologia de Compostagem}

Após o período de levantamento e tratamento dos dados gerais obtidos acerca dos resíduos orgânicos gerados no refeitório do Campus I, verificou-se que seria possível fazer a redução de cerca de $49 \%$ das emissões de "GEEs", caso fossem compostados somente os resíduos obtidos durante a preparação dos alimentos, tais como cascas de frutas, legumes, etc.

A partir dos dados obtidos, iniciou-se o processo de testes de metodologias de compostagem, em escala piloto, para que os métodos estudados fossem analisados em relação à eficiência, tempo de compostagem, entre outros parâmetros, de modo a compará-los e definir o melhor método a ser aplicado efetivamente na compostagem geral (de escala média) dos resíduos orgânicos gerados pelos restaurantes universitários dos campi I e II do CEFET-MG, bem como orgânicos oriundos de folhas, gramados e podas de árvores dos jardins da instituição.

\subsubsection{Compostagem em leira, modelo "Windrow"}

Para o início dos trabalhos de Compostagem foi utilizado o somatório dos resíduos orgânicos gerados pelos restaurantes universitários (RUs) dos campi I e II do CEFET-MG durante 5 dias (16/11/2015 à 20/11/2015). Todo o resíduo foi armazenado numa sala refrigerada no Campus I até o momento de montagem da leira de compostagem no Campus II.

A composteira foi montada no dia 20/11/2015 em modelo "Windrow" (leira), com formato trapezoidal, diretamente sobre o solo. Para a sua montagem foram utilizados $215 \mathrm{~kg}$ de compostos orgânicos oriundos do preparo da alimentação dos refeitórios, além de $176 \mathrm{~kg}$ de resíduos oriundos de podas de árvores e manutenção dos jardins da instituição. 
A leira foi montada em camadas, intercalando resíduos de podas $(15 \mathrm{~cm})$ e resíduos orgânicos dos RUs $(5 \mathrm{~cm})$, sendo que, ao final de cada camada houve irrigação. Este procedimento foi realizado continuamente até que a leira atingisse aproximadamente $1,2 \mathrm{~m}$ de altura, com volume inicial de $1,17 \mathrm{~m}^{3}$.

A leira foi revolvida e irrigada com 15 e 60 dias após sua montagem. O processo foi finalizado no dia 10/03/2016, quando a temperatura da leira se igualou à temperatura ambiente. Assim, o composto obtido foi peneirado e, a partir dos valores de massa foi possível estabelecer uma proporção de aproveitamento.

\subsubsection{Compostagem dos resíduos verdes}

Nesse método foram utilizadas 3 composteiras dentro de "bags" de ráfia $(90 \mathrm{x}$ $90 \times 120 \mathrm{~cm}$ ) de forma retangular. Na primeira composteira utilizaram-se $68 \%$ de resíduos de jardim (96 kg) e 32\% de resíduos de cortes de frutas $(46,1 \mathrm{~kg})$. Na segunda composteira foram utilizados $70 \%$ de resíduos de jardim $(96 \mathrm{~kg}), 22 \%$ de cortes de frutas $(31,4 \mathrm{~kg})$ e $8 \%$ de composto orgânico $(10,6 \mathrm{~kg})$. A terceira composteira foi construída utilizando-se $100 \%$ resíduos de jardim (96 kg). Os diferentes resíduos foram dispostos em camadas intercaladas. No término de cada camada, em cada uma das 3 composteiras, foi realizada irrigação. A montagem das composteiras foi realizada nos dias 21/10/2016 e 28/10/2016.

As composteiras foram irrigadas e revolvidas de 15 em 15 dias após a sua montagem. A compostagem foi conduzida durante o período de 21/10/2016 a 13/02/2017 (aproximadamente 120 dias). O composto foi peneirado e, a partir dos valores de massas $(\mathrm{kg})$ foi possível estabelecer uma proporção de aproveitamento e redução do volume inicial dos resíduos.

\section{RESULTADOS E DISCUSSÃO}

Os resultados de cada etapa desenvolvida do projeto possibilitou ao subgrupo, "Compostagem", realizar o planejamento da subsequente. Foram considerados os aspectos positivos e negativos a fim de realizar as adequações necessárias, de modo a subsidiar uma proposição de gestão de resíduos orgânicos mais adequada à instituição. A seguir são relatados os objetivos, resultados e conclusões de cada etapa. 


\subsection{Diagnóstico do quantitativo de resíduos orgânicos}

Esta etapa teve por objetivo avaliar o efeito dos resíduos orgânicos gerados no refeitório do CEFET-MG sobre a emissão de gases de efeito estufa; além de propor medidas de redução do desperdício de alimentos e de implantação da reciclagem.

No período de uma semana foram servidas 8375 refeições, com um desperdício de $810,3 \mathrm{~kg}$, representando $19 \%$ do total de alimentos necessários ao consumo. Utilizando-se uma planilha de cálculo do Modelo de Redução de Resíduos da Agência de Proteção Ambiental dos Estados Unidos, verificou-se que essa quantidade de alimentos descartados e dispostos em aterro sanitário correspondeu à emissão de 1,17 tCO2eq. A compostagem destes resíduos reduziria em $49 \%$ essas emissões, considerando-se apenas os resíduos gerados no preparo dos alimentos.

Diante disso, ficou claro a importância da implementação de programas de redução de resíduos orgânicos no refeitório do CEFET-MG, além de medidas para mitigar a geração dos gases de efeito estufa, como por exemplo, a compostagem in loco.

\subsection{Compostagem em leira, modelo "Windrow"}

Posteriormente, foi realizada a primeira composteira in loco, objetivando avaliar a viabilidade de compostagem dos resíduos orgânicos gerados nos restaurantes universitários dos Campi I e II do Centro Federal de Educação Tecnológica de Minas Gerais (CEFET-MG), através do monitoramento dos parâmetros pH, temperatura e umidade durante o processo.

A compostagem foi realizada na estação chuvosa, com ocorrência de precipitações constantes, o que se refletiu nos teores de umidade acima do ideal no início da compostagem e em temperaturas máximas abaixo de $60^{\circ} \mathrm{C}$, na fase termófila. No entanto, não foi observada indícios de anaerobiose, como odores desagradáveis ou lixiviação de chorume. $\mathrm{O}$ pH manteve o comportamento correspondente às diferentes fases de decomposição dos materiais orgânicos. A maturação do composto ocorreu aproximadamente aos 120 dias. Após o peneiramento, obteve-se um aproveitamento de $73,55 \%$ do composto. 


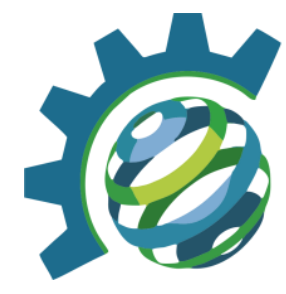

Concluiu-se que foi possível a produção de composto orgânico, sem a geração de odores ou atração de vetores e outros animais.

\subsection{Compostagem em resíduos verdes}

Devido à grande quantidade de resíduos verdes no campus II, o que tem gerado um custo devido à locação de caçambas para retirada desses resíduos, foi realizado um experimento com estes resíduos, avaliando a adição de diferentes proporções de materiais (cascas de frutas e composto orgânico finalizado) para acelerar o processo de compostagem.

Observou-se que os tratamentos com a adição de casca de fruta e o composto orgânico mostraram uma bioestabilização em menor tempo. Pôde-se concluir que ao adicionar resíduos ricos em nitrogênio (cascas de frutas) e composto orgânico maturado aos resíduos de jardim (podas de gramados e árvores) na proporção de 1:3, respectivamente, possibilitou uma atividade microbiana mais ativa na decomposição dos resíduos.

\section{CONCLUSÕES/RECOMENDAÇÕES}

Apesar dos fatores limitantes enfrentados em cada etapa do projeto (dificuldades de apoio de pessoal por parte dos restaurantes e do setor responsável pela manutenção dos jardins, a restrição de espaço físico e de ferramentas adequadas de trabalho), os resultados técnicos obtidos, até o momento, mostram-se satisfatórios.

O apoio da instituição é fundamental para a implementação da compostagem. Até o momento, os trabalhos tiveram um caráter experimental, que muito agregou em conhecimento técnico e acadêmico aos alunos e professores relacionados, no entanto, a responsabilidade da adequada destinação dos resíduos orgânicos precisa ser assumida por toda a comunidade da instituição, em atendimento à Política Nacional de Resíduos Sólidos e ao Plano Municipal de Resíduos de Belo Horizonte. 


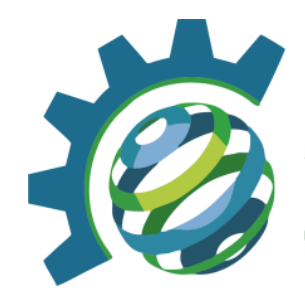

\section{REFERÊNCIAS BIBLIOGRÁFICAS}

\section{Artigo de periódico}

CUNHA, R. G. T.; TORRES, F. L.; LEMES, R. R.; MAGALHÃES, T. A. Sistema de

Gestão Ambiental para Resíduos Sólidos Orgânicos. ALFENAS (MG), 2013.

Universidade Federal de Alfenas.

TAUCHEN J. \& BRANDLI L.; A Gestão Ambiental em Instituições de Ensino Superior: Modelo para implantação em Campus Universitário. 2006.

\section{Monografia, dissertação e tese}

MASSUKADO, L. M. Desenvolvimento do processo de compostagem em unidade descentralizada e proposta de software livre para o gerenciamento municipal dos resíduos sólidos domiciliares. 2008. 204 p. Tese (Doutorado em Ciências da engenharia ambiental) - Escola de Engenharia de São Carlos, Universidade de São Paulo, São Carlos.

\section{Trabalho em evento}

LELLIS, I. C.; DUARTE, F. A. P.; FREITAS, J. E.; VICTORIANO, J. T.; ZAGO, V. C. P. 2016. "Projeto piloto de compostagem nos campi I e II do CEFET-MG", p. 947-958. In: Anais do XIV Encontro Nacional de Estudantes de Engenharia Ambiental [= BlucherEngineeringProceedings v.3 n.2]. São Paulo: Blucher, 2016.

\section{Internet}

BRASIL, 2012. Ministério do Meio Ambiente. Gestão de Resíduos Orgânicos, 2012. Disponível em: http://www.mma.gov.br/cidades-sustentaveis/residuossolidos/gest\%C3\%A3o-de-res\%C3\%ADduos-org\%C3\%A2nicos\#o-que-sao-residuosorganicos. Acesso em: 27 Mai. 2017.

INMETRO. Instituto de metrologia, qualidade e tecnologia. Tabelas de consumo/eficiência energética. Disponível em: <http://www.inmetro.gov.br/consumidor/ tabelas.asp>. Acessado em: 25 Mai. 2015. 
SEEG. Contexto. 2016. Disponível em: <http://seeg.eco.br/contexto/>. Acesso em: 27 maio 2017. 